\title{
The Knowns and Unknowns of Contemporary Statin Therapy for Familial Hypercholesterolemia
}

\author{
Jing Pang ${ }^{1} \cdot$ Dick C. Chan ${ }^{1}$ (D) - Gerald F. Watts ${ }^{1,2}$ \\ Published online: 1 September 2020 \\ (C) Springer Science+Business Media, LLC, part of Springer Nature 2020
}

\begin{abstract}
Purpose of Review Statins are first-line therapy for lowering low-density lipoprotein (LDL) cholesterol in familial hypercholesterolemia $(\mathrm{FH})$, particularly in heterozygous patients. We review advances and new questions on the use of statins in FH.

Recent Findings Cumulative evidence from registry data and sub-analyses of clinical trials mandates the value of statin therapy for prevention of atherosclerotic cardiovascular disease (ASCVD) in FH. Statins are safe in children and adolescents with FH, with longer term cardiovascular benefits. The potentially toxic effects of statins in pregnancy need to be considered, but no association has been reported in prospective cohort studies with birth defects. There is no rationale for discontinuation of statins in elderly FH unless indicated by adverse events. FH is undertreated, with $>80 \%$ of statin-treated FH patients failing to attain LDL cholesterol treatment targets. This may relate to adherence, tolerability, and genetic differences in statin responsiveness. Statin treatment from childhood may reduce the need for stringent cholesterol targets. Combination of statins with ezetimibe and PCSK9 inhibitors significantly improves the efficacy of treatment. Whether statin use could improve the clinical course of FH patients with COVID-19 and other respiratory infections remains an unsolved issue for future research.

Summary Statins are the mainstay for primary and secondary prevention of ASCVD in FH. Sustained long-term optimal statin treatment from an early age can effectively prevent ASCVD over decades of life. Despite their widespread use, statins merit further investigation in $\mathrm{FH}$.
\end{abstract}

Keywords Familial hypercholesterolemia $\cdot$ Cardiovascular disease $\cdot$ Treatment $\cdot$ Statins $\cdot$ Adults $\cdot$ Children

\section{Introduction}

Familial hypercholesterolemia (FH) is the most common and serious form of inherited high cholesterol that markedly accelerates the onset of atherosclerotic cardiovascular disease (ASCVD), principally coronary artery disease [1,2]. Patients with FH have a life-long burden of elevated low-density lipoprotein (LDL) that warrants aggressive cholesterol lowering [3]. Statins are frontline for the prevention and treatment of ASCVD in FH [1, 4-9]. We review novel aspects of the use of

This article is part of the Topical Collection on Statin Drugs

Gerald F. Watts

gerald.watts@uwa.edu.au

1 School of Medicine, Faculty of Health and Medical Sciences, University of Western Australia, Perth, WA, Australia

2 Lipid Disorders Clinic, Cardiometabolic Services, Department of Cardiology, Royal Perth Hospital, GPO Box X2213,

Perth, WA 6847, Australia statins in the management of FH and explore new avenues for future research.

\section{Review Criteria}

A search for original articles was performed in the PubMed database using the following key terms: 'statins', 'HMG-CoA reductase inhibitors', 'familial hypercholesterolemia', 'primary hypercholesterolemia', 'LDL-cholesterol', 'LDL receptor', 'treatment', and 'cardiovascular disease', either alone or in combination. All articles selected were in the English language, full-text papers, with no restriction applied to the date of publication.

\section{Genetic and Metabolic Perspectives}

FH is an autosomal dominant disorder with a gene dosing effect, in which homozygotes are more adversely affected 
than heterozygotes [1]. In two recent meta-analyses, the prevalence of FH in the general population was approximately 1 in $312[10,11]$. The majority of FH cases $(>90 \%)$ are caused by mutations in the LDL receptor (LDLR), with > 1000 pathogenic or likely pathogenic variants described. About $5 \%$ of FH cases are due to mutations in the LDL Receptor binding region of $A P O B$ gene, with gain-of-function $P C S K 9$ mutations found in $1-2 \%$ of $\mathrm{FH}$ cases [12]. Rare mutations in STAP1 and LDLAP1 genes have also been described in FH.

$\mathrm{FH}$ is a genetic disorder of LDL metabolism. During normal lipid regulation, LDL particles bind to LDL Receptors expressed on the liver surface via their ligand apolipoprotein B-100 (apoB) molecule. The complex is internalised and degraded in the lysosomal compartment. Proprotein convertase subtilisin/kexin type 9 (PCSK9) decreases recycling and increases degradation of the LDL Receptors. Accordingly, defects in any of these pathways can therefore potentially impair the function of LDL Receptors resulting in reduced clearance of LDL particles from the circulation and accumulation of LDL particles in the circulation.

Defect in the LDL Receptor also modulates lipoprotein metabolism other than LDL particles. Increased secretion of very-low-density lipoprotein (VLDL) particles, decreased catabolism of chylomicron and remnants, and increased catabolism of high-density lipoprotein (HDL) have been reported in patents with FH $[13,14]$. The effect of FH on cholesterol efflux capacity has shown conflicting results [15-17], probably owing to differences in assay protocols and patient characteristics. Elevated plasma lipoprotein(a) (Lp(a)) is frequently seen in patients with $\mathrm{FH}$, especially those with ASCVD [18, 19]. However, the mechanism for increased $L p(a)$ levels is controversial but may be related to the type of $L D L R$ mutation [19].

\section{Statins}

Statins selectively inhibit hydroxyl-methylglutaryl coenzyme A (HMG-CoA) reductase, a key enzyme in the synthesis of cholesterol in the liver. This is followed by the activation of the sterol regulatory element-binding protein 2 , a transcription factor which subsequently upregulates the expression of LDL Receptors. This upregulation leads to increased uptake of LDL and other apoB containing lipoproteins, including triglyceride-rich lipoproteins from the circulation.

The currently available statins include pravastatin, lovastatin, simvastatin, fluvastatin, atorvastatin, rosuvastatin, and pitavastatin, with LDL cholesterol-lowering effects of 30$60 \%$ across different types and doses of statins [4, 5]. Highintensity statin therapy (e.g. atorvastatin 40-80 mg/day or rosuvastatin $20-40 \mathrm{mg}$ /day) can lower LDL cholesterol by $50-60 \%$, whereas moderate-intensity statin therapy (e.g. atorvastatin $10-20 \mathrm{mg} /$ day or pravastatin $40-80 \mathrm{mg} /$ day) can reduce LDL cholesterol by $30-40 \%$. Pitavastatin is the newest statin in the market that lowers LDL cholesterol by $30-45 \%$ across its dose range of 1 to $4 \mathrm{mg} /$ day. The therapeutic efficacy of statins is dependent on LDL Receptor function, with less effectiveness in LDL Receptor-negative (deficient receptors) than in receptor-defective (defective receptors) homozygous FH $[20,21]$. The therapeutic effect of statins may be modified by variation in genetic factors. FH patients with the $A P O E^{* 4}$ allele are poorer responders to statin treatment than those that are $A P O E^{*} 2$ or $A P O E^{*} 3$ carriers [22]. Loss-of-function (LOF) variants in PCSK 9 are associated with an increased response to statin therapy, up to 55\% [23]. Data from genome-wide association studies (GWAS) also demonstrate that $\sim 5-10 \%$ of the variation in LDL cholesterol response to statin treatment is associated with the interaction with some genetic variants, such as ApoE, LPA, SORT1/CELSR2/ PSRC1, and SLCO1B1 [24]. However, the collective effect of genetic variants on the therapeutic responses to statins in $\mathrm{FH}$ requires further investigation.

\section{Children and Adolescents}

The short- and intermediate-term efficacy and tolerance of statins in children and adolescents have been confirmed by observational studies and meta-analyses [25-27]. Statin treatment is generally well tolerated, with good adherence to treatment [28]. Long-term follow-up of children treated with pravastatin demonstrated an excellent adherence and tolerance with $>80 \%$ remaining on statins and only $1.5 \%$ discontinued treatment due to adverse effects [29]. However, further studies are required to assess the life-long safety of statins commenced in childhood.

Several statins, including simvastatin, lovastatin, atorvastatin, pravastatin, fluvastatin, and rosuvastatin, are approved for use in FH children in the USA and Europe [30, 31]. Current guidelines recommend that children with homozygous FH should be treated as early as possible when the diagnosis is made. Children who are heterozygous for FH should be initiated at the lowest recommended dose (such as pravastatin $20 \mathrm{mg}$, atorvastatin $10 \mathrm{mg}$, and rosuvastatin $5 \mathrm{mg}$ ) and up-titrated according to the LDL cholesterol-lowering response and tolerability from 8 to 10 years of age (Table 1) $[4 \cdot, 6,32 \bullet, 33]$.

In the CHARON study, rosuvastatin treatment (starting at $5 \mathrm{mg}$ daily, with up-titration to $10 \mathrm{mg}$ at age 6-9 years or $20 \mathrm{mg}$ at age of 10-17 years) for 2 years resulted in significantly less progression of increased carotid intima-media thickness (IMT) in children with heterozygous FH than their untreated unaffected sibling; there was no significant difference in carotid IMT detected between the 2 groups after 2 years of rosuvastatin [34, 35]. A 10-year follow-up of statin-treated FH children has also been associated with thinning and normalisation of carotid IMT 
Table 1 LDL cholesterol targets for children and adolescents in familial hypercholesterolemia

\begin{tabular}{|c|c|}
\hline & Recommendations \\
\hline $\mathrm{ESC} / \mathrm{EAS}[4 \bullet]$ & $\begin{array}{l}\text { - From } 8 \text { to } 10 \text { years of age: a level of LDL cholesterol }<3.5 \mathrm{mmol} / \mathrm{L} \text { at }>10 \text { years of age } \\
\text { - At younger ages: a } 50 \% \text { reduction in LDL cholesterol from baseline }\end{array}$ \\
\hline CCS [6] & $\begin{array}{l}-8-10 \text { years of age: statin therapy be considered if } \mathrm{LDL} \text { cholesterol } \geq 4.9 \mathrm{mmol} / \mathrm{L} \text { or } \\
\geq 4.1 \mathrm{mmol} / \mathrm{L} \text { years if there are additional co-morbidities or family history premature } \mathrm{CAD}\end{array}$ \\
\hline $\begin{array}{l}\text { HEART UK } \\
{[32 \bullet]}\end{array}$ & $\begin{array}{l}\cdot<10 \text { years of age: a } 30-50 \% \text { reduction in LDL cholesterol from baseline or a level } \\
<3.5 \mathrm{mmol} / \mathrm{L} \\
\cdot \geq 10 \text { years of age: a } 50 \% \text { reduction in LDL cholesterol from baseline or a level } \\
<3.5 \mathrm{mmol} / \mathrm{L} \\
\cdot \geq 14 \text { years of age: a target LDL cholesterol concentration of }<2.5 \mathrm{mmol} / \mathrm{L} \text { over the next } \\
\quad 3-5 \text { years if there are additional co-morbidities or family history premature } \mathrm{CAD}\end{array}$ \\
\hline JAS [33] & $\begin{array}{l}\cdot \geq 10 \text { years of age: a } 50 \% \text { reduction in LDL cholesterol from baseline or a level } \\
<3.6 \mathrm{mmol} / \mathrm{L}\end{array}$ \\
\hline
\end{tabular}

$C A D$ coronary artery disease, CCS Canadian Cardiovascular Society, ESC/EAS European Society of Cardiology/ European Atherosclerosis Society, HEART UK Hyperlipidaemia Education and Atherosclerosis Research Trust United Kingdom, JAS Japan Atherosclerosis Society, $L D L$ low-density lipoprotein, NLA National Lipid Association
[29]. A more recent study has shown that children commenced on low-to-moderate intensity statin (pravastatin 20-40 mg daily) had a $1 \%$ incidence of cardiovascular events after a 20 -year follow-up compared with $26 \%$ in their affected parents who were treated with statins later in life [36••]. This is despite the reduction in LDL cholesterol of a modest $32 \%$, which underscores the value of earlier and sustained statin therapy without achieving the current guideline-recommended targets. This notion is also supported by Mendelian randomisation studies that long-term exposure to lower LDL cholesterol beginning early in life is associated with a substantially greater reduction in the risk of ASCVD than the beneficial effect of lowering LDL cholesterol in adults treated over 5 years in later life [37, 38].

\section{Adults}

The efficacy and safety of statin use in adults for primary and secondary prevention of ASCVD is well established [4-9]. While all statins can reduce LDL cholesterol in heterozygous $\mathrm{FH}$, statin monotherapy is insufficient to achieve the guideline-recommended LDL cholesterol levels [38]. Randomised, placebo-controlled trials with $\mathrm{FH}$ patients have not been undertaken for ethical reasons. Nonetheless, observational registry data and sub-analyses of clinical trials have contributed to increasing evidence of the value of statins in $\mathrm{FH}$ [39-45].

In a large cohort studies from the Netherlands, moderateintensity statin therapy (simvastatin or atorvastatin with a mean daily dose of $33 \mathrm{mg}$ and $49 \mathrm{mg}$, respectively) reduced ASCVD mortality by $76 \%$ [40]. In another follow-up cohort study from South Africa, lipid-lowering therapy, predominantly statin therapy $(40 \mathrm{mg}$ of rosuvastatin or $80 \mathrm{mg}$ of atorvastatin daily), was associated with delayed cardiovascular events and prolonged survival in patients with homozygous FH by $50 \%$ and $65 \%$, respectively [44]. Moderate-tohigh-intensity statins (simvastatin $40 \mathrm{mg}$ or atorvastatin $40 \mathrm{mg}$ ) were shown to confer a relative reduction in coronary risk of $44 \%$ in asymptomatic heterozygous FH patients [3]. Similarly, data from the UK Simon Broome Registry have also confirmed the benefit of statins in reducing coronaryrelated mortality, with a larger reduction in coronary mortality in women than in men $[41,45]$. Additionally, $\mathrm{FH}$ patients on long-term statin treatment have been shown to exhibit similar degrees of carotid artery plaques and IMT to subjects in the general population [46]. Aggressive LDL cholesterol reduction by high-intensity statin (atorvastatin $80 \mathrm{mg}$ ) over 2 years was accompanied by a regression of carotid IMT in patients with FH [47]; however, such benefit was not observed with conventional statin therapy (simvastatin $40 \mathrm{mg}$ ). This observation is consistent with current guideline recommendation that $\mathrm{FH}$ adults should be treated with the maximal tolerated dose of a high-intensity statin. In a recent study from Japan, pitavastatin (2 mg/day) compared with atorvastatin $(10 \mathrm{mg} /$ day) significantly reduced cardiovascular events in hypercholesterolemic patients [48]. However, the cardiovascular benefit of pitavastatin has not yet been specifically studied in $\mathrm{FH}$.

In a sub-analysis from the West of Scotland Coronary Prevention Study (WOSCOPS), pravastatin reduced the risk of ASCVD during the initial 5-year trial as well as over a total of 20 years post-trial follow-up in participants who were hypercholesterolemic (LDL cholesterol $>4.9 \mathrm{mmol} / \mathrm{L}$ ) and free from ASCVD [49]. The post-trial legacy effect of statins has also been reported in a meta-analysis showing significant beneficial effects on cardiovascular and all-cause mortality [42••]. Taken together, these analyses provide robust evidence for the 
long-term benefits of lowering LDL cholesterol, particularly for the primary prevention of ASCVD, among individuals with hypercholesterolemia, and particularly those with $\mathrm{FH}$.

\section{Pregnancy}

Pregnancy is associated with changes in lipid metabolism that are essential for fetal growth and development. In a study of 22 pregnant women with FH, LDL cholesterol increased significantly between baseline and gestational week 36 by $30 \%$ [50]. The absolute increase in LDL cholesterol is markedly higher in women with than without FH during pregnancy [50, 51]. In a registry-based study, women with FH did not appear to have a higher risk of pregnancy complications (preterm delivery, low infant birth weight, or congenital malformations) than women in general [52].

The treatment of FH in pregnancy is challenging because statins are contraindicated during pregnancy owing to the potential adverse effects of statins on fetal development. Current guidelines recommend that all women of child-bearing age with FH on lipid-lowering therapy should receive prepregnancy counselling as well as contraception advice [4-6, 53]. Statins should be discontinued 3 months prior to planned conception and during pregnancy and lactation, but resumed immediately after the completion of breast feeding. Women who become pregnant while on statin therapy should stop the statin immediately and undergo fetal assessment. Bile acid sequestrants are the only safe agents in FH during pregnancy but only modestly lower plasma LDL cholesterol levels and can elevate triglycerides, reduce absorption of fat-soluble vitamins, and cause gastrointestinal upset. It is noteworthy that there is no strong evidence between statin exposure in pregnancy and increased risk of pregnancy complications in both homozygous and heterozygous women [52, 54]. However, pregnancy and lactation lead to the disadvantage of fewer effective years of treatment in women. Hence, early diagnosis and treatment of FH in girls are required to reduce the overall cholesterol burden related to periods off statin therapy during pregnancy and lactation. Further studies of the impact of multiple frequencies and cholesterol life years on CAD events are required.

\section{Elderly}

The efficacy and safety of statin therapy in older adults are unclear. In a meta-analysis of 28 randomised trials, statin use was safe and well tolerated and associated with a significant reduction in major ASCVD events in people older than 75 [55•]. The European Society of Cardiology/European Atherosclerosis Society (ESC/EAS) guidelines recommend that elderly patients should be started with statin at a low dose and then titrate with caution to achieve target lipid levels as the younger subjects [4•]. There is no rationale for discontinuation of maximal tolerated dose of statin and non-statin therapy in elderly with FH unless indicated by adverse events. However, more information is required on value of statin therapy in elderly FH from registry data.

\section{Statin Safety and Tolerance}

A number of patients taking statins experience significant side effects that result in a partial or complete intolerance to the drug [56 ]. Hence, diagnosis and management of statin intolerance may present a major challenge in the care of FH. There are little data regarding statin intolerance in FH. In the CASCADE-FH Registry [57], 15\% of patients with heterozygous FH did not receive statin treatment due to statin intolerance or allergy. Data from the UK Simon Broome Registry have reported that $6.8 \%$ of $\mathrm{FH}$ patients were not prescribed statin therapy because of statin intolerance [45]. Statin intolerance in children has not been specificity-investigated. However, use of statin in children with FH is generally safe and well tolerated with no difference in liver function and myopathy compared with placebo in children [27••]. It is noteworthy that most of the patients with statin-associated muscle symptom (SAMS) can continue to tolerate statins using a stepby-step approach given complete intolerance to statin therapy affects only $3-5 \%$ patients [58].

\section{Adherence}

The effectiveness of statin therapy is limited by poor adherence with up to $50 \%$ of eligible patients not currently taking statins. Poor adherence to statin therapy or discontinuation has been shown to be associated with a significant increased risk of ASCVD [59,60]. However, there are limited data regarding statin adherence data in FH. In a study of FH patients with a statin prescription [61], poor adherence of statins was reported by $11 \%$ of the patients. Similar findings were found in young adult $\mathrm{FH}$ patients showing a nonadherence rate of $22 \%$ to statin treatment [28]. Although statin adherence rates in $\mathrm{FH}$ patients are relatively high, a substantial proportion of patients may fall short of full compliance or follow regime inconsistently owing to their beliefs about medication harm and overuse, treatment effectiveness, and social influence [62]. Intense media discussion over the risks-benefit balance of statins resulted in a rise in the proportion of patients who discontinued to take statins $[63,64]$. This may be particularly crucial in young $\mathrm{FH}$ in whom poorer adherence and statin initiation are frequently noted [60]. Hence, the care of FH must be patient-centred to improve the quality of decision-making processes, and this may be facilitated by the use of decision aids. 
Health literacy issues in FH must also be addressed to ensure adherence to therapies $[31,65 \bullet \bullet, 66]$.

\section{Cholesterol Responsiveness in Racial Groups}

The dose of statins and the degree of LDL cholesterol reduction achieved with statins are different between Asian and Caucasian patients $[67,68]$. However, there are limited data regarding racial differences in response to statins in $\mathrm{FH}$. Current guidelines recommend that $\mathrm{FH}$ patients should be treated with maximal tolerant dose of statins. However, it is questionable whether comparable dose of statin, for example $40 \mathrm{mg}$ rosuvastatin, should be used in $\mathrm{FH}$ patients with Asian ethnicity given the potential greater systemic exposure to rosuvastatin and thereby higher risk of severe myopathy [69, 70]. The efficacy and safety of pitavastatin in Japanese and European children and adolescents with FH are comparable, suggesting no significant ethnic differences on the therapeutic responses to pitavastatin [71]. Hence, more research is required to investigate and compare the pharmacokinetics of different statins in $\mathrm{FH}$ patients among different racial groups.

\section{Statins and Lipoprotein(a)}

Elevated Lp(a) is a significant amplifier of ASCVD risk in $\mathrm{FH}$ $[19,72]$. About $30 \%$ of FH patients have an elevated concentration of $\mathrm{Lp}(\mathrm{a})$ of $>0.5 \mathrm{~g} / \mathrm{L}[18,19]$. This leads to an extremely highly elevated ASVD risk due to life-long elevated levels of both LDL and Lp(a) particles. In a cross-sectional analysis from the SAFEHEART registry, patients with FH, especially those with ASCVD, had higher Lp(a) plasma levels compared with their unaffected relatives. $\mathrm{Lp}(\mathrm{a})$ is a significant predictor of ASCVD in FH independent of the type of $L D L R$ mutation [19]. However, statin therapy does not affect Lp(a) levels. In some studies, statin treatment may even increase Lp(a) levels [73••], particularly in those with smaller apolipoprotein(a) [apo(a)] isoform [74]. The effect of statin on Lp(a) level may depend on the type and dose of statins. In a recent meta-analysis, atorvastatin $(80 \mathrm{mg})$, rosuvastatin $(40 \mathrm{mg})$, and pravastatin $(40 \mathrm{mg}$ ) significantly increased Lp(a) levels, whereas atorvastatin $(10 \mathrm{mg})$ and pitavastatin $(2 \mathrm{mg})$ trended to decrease $\operatorname{Lp}(\mathrm{a})$ levels [73••]. However, none of these statin trials were specific for patients with $\mathrm{FH}$ or elevated $\mathrm{Lp}(\mathrm{a})$. Since routine measurement of LDL cholesterol levels includes a proportion of $\mathrm{Lp}$ (a)-derived cholesterol [75], FH patients with elevated $\mathrm{Lp}$ (a) may derive a less than optimal benefit with statins, because statin treatment may result not only in an increase in $\mathrm{Lp}$ (a) levels but also in a decrease in apparent response to LDL cholesterol lowering. Whether these effects play a role in the residual risk in FH patients treated with statins merits further investigation. These observations also foreshadow the value of PCSK9 inhibitors and/or other specific agents (e.g. apolipoprotein(a) antisense oligonucleotides) for lowering $\mathrm{Lp}(\mathrm{a})$ in $\mathrm{FH}$ against a background of statin therapy.

\section{Statins and Coronary Artery Calcium Score}

Imaging of preclinical atherosclerosis may currently be the most valuable tool for risk re-stratifying patients with $\mathrm{FH}$. Coronary artery calcium (CAC) scoring is a noninvasive measure of atherosclerotic plaque burden with a CAC (Agatston) value of $>100$ defined as high vascular plaque burden. $\mathrm{FH}$ patients with high CAC score should be considered at very high cardiovascular risk. Several studies have shown that FH individuals have greater $\mathrm{CAC}$ burden than normolipidemic controls [76, 77]. CAC scores have also been shown to be associated with incident ASCVD events in asymptomatic heterozygous $\mathrm{FH}$ patients receiving standard lipid-lowering therapies (70\% of statin use at baseline) [78••]. Hence, CAC scores can be used to improve the accuracy of ASCVD risk prediction in $\mathrm{FH}$ and allow shared decision-making and improve adherence to statin therapy. FH patients with high CAC should be treated more aggressively, including high-intensity statins and other potent cholesterol-lowering agents, such as PCSK9 inhibitors.

Several studies suggest that statins promote CAC progression $[79,80]$. However, an increase in CACS may not indicate an increased total burden of vascular plaque in patients treated with statins. It is possible that statins increase coronary calcification possibly reflecting plaque stabilisation by reducing the progression of plaque volume and increasing density of plaque calcium, which could lead to higher CAC scores, as evidenced by in vivo IVUS imaging [79-81]. Hence, serial measurements of CAC during follow-up may not have clinical value in $\mathrm{FH}$ patients receiving long-term statin therapy.

Noninvasive computed tomography coronary angiography (CTCA) is another noninvasive imaging modality to assess coronary atherosclerosis [82]. This technique can integrate the effect of LDL cholesterol life years, guide therapy, improve patient adherence, and assist in prioritising further cardiac investigations [82]. However, its precise clinical and economic value remains to be demonstrated in FH.

\section{Statins and COVID-19}

The current coronavirus pandemic is an outbreak of coronavirus disease 2019 (COVID-19) caused by severe acute respiratory syndrome coronavirus 2 (SARS-CoV-2). Observational studies have found that people with cardiovascular co-morbidities are more likely to be infected with SARS-CoV-2 and to develop severe symptoms [83]. 
Table 2 LDL cholesterol targets for adults in familial hypercholesterolemia, adapted from Watts 2020 [65••]

\begin{tabular}{|c|c|c|c|c|c|c|c|}
\hline Treatment targets & ESC/EAS [4•] & AHA/ACC $[5 \bullet]$ & CCS [6] & NLA [7] & JAS [8] & AACE/ACE [9] & NICE $[89,90]$ \\
\hline \multicolumn{8}{|l|}{ Primary prevention } \\
\hline \multicolumn{8}{|l|}{ Primary target: LDL cholesterol } \\
\hline Relative reduction $(\%)$ & $\geq 50$ & - & 50 & $\geq 50$ & $\geq 50$ & - & $>50$ \\
\hline Absolute level (mmol/L) & $<1.8^{\mathrm{a}}$ & $<2.6$ & $<2.5$ & $<2.6$ & $<2.6$ & $<1.8$ & - \\
\hline \multicolumn{8}{|l|}{ Secondary targets: } \\
\hline Absolute non-HDL cholesterol level (mmol/L) & $<2.6$ & - & - & $<3.4$ & - & $<2.6$ & - \\
\hline Absolute apoB level (mg/dL) & $<80$ & - & - & $<90$ & - & $<80$ & - \\
\hline \multicolumn{8}{|l|}{ Secondary prevention } \\
\hline \multicolumn{8}{|l|}{ Primary target: LDL cholesterol } \\
\hline Relative reduction $(\%)$ & $\geq 50$ & - & - & $\geq 50$ & - & - & $>50$ \\
\hline Absolute level (mmol/L) & $<1.4$ & $<1.8$ & $<2.0$ & $<1.8$ & $<1.8$ & $<1.4$ & - \\
\hline \multicolumn{8}{|l|}{ Secondary targets } \\
\hline Absolute non-HDL cholesterol level (mmol/L) & $<2.2$ & $<2.6$ & $<2.6$ & $<2.6$ & - & $<2.1$ & - \\
\hline Absolute apoB level (mg/dL) & $<65$ & - & - & $<80$ & - & $<70$ & - \\
\hline
\end{tabular}

$A A C E / A C E$ American Association of Clinical Endocrinologists/American College of Endocrinology, AHA/ACC American Heart Association/American College of Cardiology, ApoB apolipoprotein B-100, CAD coronary artery disease, CCS Canadian Cardiovascular Society, ESC/EAS European Society of Cardiology/European Atherosclerosis Society, $H D L$ high-density lipoprotein, JAS Japan Atherosclerosis Society, $L D L$ low-density lipoprotein, NICE National Institute for Health and Clinical Excellence, NLA National Lipid Association

${ }^{a}$ Lower target to $<1.4 \mathrm{mmol} / \mathrm{L}$ if there is another major risk factor (e.g. smoking, diabetes, hypertension, unequivocal atherosclerotic cardiovascular disease on imaging)

COVID-19 also exerts a high inflammatory burden that can induce risk of ASCVD, such as vascular inflammation, myocarditis, and cardiac arrhythmias. Most of these patients are taking statins for ASCVD prevention. Hence, there is an increasing interest regarding statin use in patients with COVID-19.

It is known that statins do not only exert pleiotropic effects on inflammation and oxidative stress but also favourably modulate the immune response [84]. Accordingly, statins can be used as an add-on treatment in patients with autoimmune inflammatory conditions [85]. Hence, these evidences support the continual use or even initiation of statin as an added-on treatment for COVID-19 patients. In contrast, statin use in patients with COVID-19 could increase the risk and severity of myopathies. Some statins, such as simvastatin and atorvastatin, are metabolised through CYP3A4 metabolic pathway [86]. Hence, concomitant administration of currently used CYP3A4 inhibitors for COVID-19, such as ritonavir, cobicistat, and azithromycin, may in turn increase the risk of muscle and liver toxicity and thereby develop severe symptoms [87]. Whether
Table 3 Suggestions for further research on statins, with implications for the management of familial hypercholesterolemia

\begin{tabular}{|c|c|}
\hline Research topics & Research questions \\
\hline Statin responsiveness & $\begin{array}{l}\text { What are the effects of genetic and racial variation response of LDL cholesterol to } \\
\text { different statins? }\end{array}$ \\
\hline $\begin{array}{l}\text { Children and } \\
\text { adolescents }\end{array}$ & $\begin{array}{l}\text { What is the long-term ASCVD benefit or legacy effect of early statin therapy in } \\
\text { children and adolescents? }\end{array}$ \\
\hline Safety in pregnancy & What is the safety of statins and their effect on fetal development? \\
\hline Statin intolerance & $\begin{array}{l}\text { What are the mechanisms of type and dose effect of statins on the development of } \\
\text { SAMS? }\end{array}$ \\
\hline Adherence & $\begin{array}{l}\text { What are the concerns and beliefs of patients about statin use, and how could decision } \\
\text { aids improve health literacy and the quality of decision-making process? }\end{array}$ \\
\hline Lipoprotein(a) & What are the mechanisms of statins on synthesis and clearance of $L p(a)$ particles? \\
\hline $\begin{array}{l}\text { Coronary artery } \\
\text { calcium score }\end{array}$ & $\begin{array}{l}\text { What are the mechanisms of statins on arterial calcification and the progression of } \\
\text { plaque volume? }\end{array}$ \\
\hline Statin-related therapies & $\begin{array}{l}\text { What are the mechanisms of small interfering RNA (siRNA) therapies that inhibit } \\
\text { HMG-CoA reductase on LDL metabolism? }\end{array}$ \\
\hline
\end{tabular}


statin use could improve the clinical course of FH patients with COVID-19 remains to be investigated [88•].

\section{Statins and Therapeutic Targets}

Recent recommendations for managing LDL cholesterol in adults with heterozygous $\mathrm{FH}$ are summarised in Table 2 [4-9, 89, 90]. Statin therapy should be initiated as soon as possible after a diagnosis of $\mathrm{FH}$ has been made. The most recent guidelines from the ESC/EAS and the American Association of Clinical Endocrinologists/American College of Endocrinology (AACE/ACE) have recommended very stringent LDL cholesterol targets for $\mathrm{FH}$ patients with and without ASCVD $(<1.8 \mathrm{mmol} / \mathrm{L}$ for primary prevention and $<1.4 \mathrm{mmol} / \mathrm{L}$ for secondary prevention or very high risk) [4, 9]. For FH patients with ASCVD who experience a second vascular event within 2 years, an LDL cholesterol goal < $1.0 \mathrm{mmol} / \mathrm{L}$ may be considered reasonable. Some guidelines have also specified non-HDL cholesterol and apoB levels as secondary treatments, but their usefulness in clinical practice remains to be demonstrated [4-7, 9].

However, most patients with FH cannot attain the very low absolute levels of LDL cholesterol shown in Table 2, even when receiving a high-intensity tolerant dose of statin and ezetimibe. In the SAFEHEART registry, an LDL cholesterol treatment target $<1.8 \mathrm{mmol} / \mathrm{L}$ was reached by only $1.1 \%$ and $4.7 \%$ of FH patients at entry and 5-year follow-up, respectively, despite a high percentage receiving maximal lipidlowering therapy [39]. Even with the less aggressive LDL cholesterol goals of $<2.6 \mathrm{mmol} / \mathrm{L}$ and $<1.8 \mathrm{mmol} / \mathrm{L}$ for primary and secondary prevention, respectively, registry data from the USA show that $>75 \%$ and $>80 \%$ of patients, respectively, do not achieve these targets [91•].

Difficulty in achieving LDL cholesterol targets among statin-treated $\mathrm{FH}$ patients will necessitate a third-line therapy, such as PCSK9 inhibitors. In patients with FH receiving maximal tolerated dose of statins and ezetimibe, PCSK9 inhibitors can additionally lower LDL cholesterol level by approximately $60 \%$ across all types and classes of mutation [92•]. More importantly, $>80 \%$ of patients can achieve the recommended treatment targets [93]. Current guidelines also recommend the use of PCSK9 inhibitors to treat homozygous FH patients except those with confirmed negative/negative $L D L R$ mutations. However, there is no specific data from clinical trials to evaluate the cost-effectiveness of the use of PCSK9 inhibitors for ASCVD prevention in $\mathrm{FH}$.

\section{Conclusion}

Statins are foundational treatment for FH. A heart healthy diet and lifestyle therapy and non-statin drugs are most efficacious against backbone of statin therapy. Early and optimal treatment of FH with statins is the key to improve ASCVD outcomes. Statin therapy for managing FH is cost-effective [94, 95]. However, clinical and therapeutic challenges exist in relation to statin intolerance, poor adherence, and attainment of current LDL cholesterol targets. This merits further research (Table 3). The recommended approach is early diagnosis and sustained statin treatment from childhood [96, 97], with a less stringent LDL cholesterol target. Novel therapies, such as PCSK9 inhibitors, have been proven to achieve greater reductions in LDL cholesterol and ASCVD events in high-risk patients, a finding that supports their use in patients with FH. Beyond monoclonal antibodies, PCSK9 may be targeted with small interfering RNA, such as inclisiran, which is undergoing testing in cardiovascular outcomes trials [98]. New development of SiRNA-based therapies can also be used to target HMG-CoA reductase and $\mathrm{Lp}(\mathrm{a})$ [99, 100]. This approach may in the future address the outstanding gaps in the care of FH.

\section{Compliance with Ethical Standards}

Conflict of Interest The authors declare that they have no conflict of interest.

Human and Animal Rights and Informed Consent This article does not contain any studies with human or animal subjects performed by any of the authors.

\section{References}

Papers of particular interest, published recently, have been highlighted as:

- Of importance

•- Of major importance

1. Nordestgaard BG, Chapman MJ, Humphries SE, Ginsberg HN, Masana L, Descamps OS, et al. Familial hypercholesterolaemia is underdiagnosed and undertreated in the general population: guidance for clinicians to prevent coronary heart disease: consensus statement of the European Atherosclerosis Society. Eur Heart J. 2013;34:3478-90.

2. Borén J, Chapman MJ, Krauss RM, et al. Low-density lipoproteins cause atherosclerotic cardiovascular disease: pathophysiological, genetic, and therapeutic insights: a consensus statement from the European Atherosclerosis Society Consensus Panel. Eur Heart J. 2020;41:2313-30. https://doi.org/10.1093/eurheartj/ ehz962.

3. Besseling J, Hovingh GK, Huijgen R, Kastelein JJP, Hutten BA. Statins in familial hypercholesterolemia: consequences for coronary artery disease and all-cause mortality. J Am Coll Cardiol. 2016;68:252-60.

4. Mach F, Baigent C, Catapano AL, et al. 2019 ESC/EAS Guidelines for the management of dyslipidaemias: lipid modification to reduce cardiovascular risk: The Task Force for the management of dyslipidaemias of the European Society of Cardiology 
(ESC) and European Atherosclerosis Society (EAS). Eur Heart J. 2020;41:111-88 Very recent guideline for the management of lipid disorders, including $\mathrm{FH}$.

5. Grundy SM, Stone NJ, Bailey AL, et al. 2018 AHA/ACC/ AACVPR/AAPA/ABC/ACPM/ADA/AGS/APhA/ASPC/NLA/ PCNA 2018 Guideline on the management of blood cholesterol. A report of the American College of Cardiology/American Heart Association Task Force on Clinical Practice Guidelines. J Am Coll Cardiol. 2019;73:e285-350 Very recent guideline for the management of lipid disorders, including FH.

6. Brunham LR, Ruel I, Aljenedil S, Rivière JB, Baass A, Tu JV, et al. Canadian Cardiovascular Society position statement on familial hypercholesterolemia: update 2018. Can J Cardiol. 2018;34:1553-63.

7. Jacobson TA, Ito MK, Maki KC, Orringer CE, Bays HE, Jones $\mathrm{PH}$, et al. National Lipid Association recommendations for patient-centered management of dyslipidemia: part 1 -full report. J Clin Lipidol. 2015;9:129-69.

8. Harada-Shiba M, Arai H, Ishigaki Y, Ishibashi S, Okamura T, Ogura $\mathrm{M}$, et al. Guidelines for diagnosis and treatment of familial hypercholesterolemia 2017. J Atheroscler Thromb. 2018;25:751-70.

9. Jellinger PS, Handelsman Y, Rosenblit PD, Bloomgarden ZT, Fonseca VA, Garber AJ, et al. American Association of Clinical Endocrinologists and American College of Endocrinology Guidelines for management of dyslipidemia and prevention of cardiovascular disease. Endocr Pract. 2017;23(s2):1-87.

10.• Beheshti SO, Madsen CM, Varbo A. Nordestgaard BG. Worldwide prevalence of familial hypercholesterolemia: metaanalyses of 11 million subjects. J Am Coll Cardiol. 2020;75: 2553-26 Updated information on the prevalence of FH.

11.• Hu PW, Dharmayat KI, Stevens CAT, et al. Prevalence of familial hypercholesterolemia among the general population and patients with atherosclerotic cardiovascular disease: a systematic review and meta-analysis. Circulation. 2020;141:1742-59 Updated information on the prevalence of $\mathrm{FH}$.

12. Sharifi M, Futema M, Nair D, Humphries SE. Genetic architecture of familial hypercholesterolaemia. Curr Cardiol Rep. 2017;19:44.

13. Chan DC, Watts GF. Postprandial lipoprotein metabolism in familial hypercholesterolemia: thinking outside the box. Metabolism. 2012;61:3-11.

14. Ooi EMM, Barrett PHR, Watts GF. The extended abnormalities in lipoprotein metabolism in familial hypercholesterolemia: developing a new framework for future therapies. Int J Cardiol. 2013;68: 1811-8.

15. Adorni MP, Zimetti F, Puntoni M. Cellular cholesterol efflux and cholesterol loading capacity of serum: effects of LDL-apheresis. J Lipid Res. 2012;53:984-9.

16. Versmissen J, Vongpromek R, Yahya R. Familial hypercholesterolaemia: cholesterol efflux and coronary disease. Eur J Clin Investig. 2016;46:643-50.

17. Ogura M, Hori M, Harada-Shiba M. Association between cholesterol efflux capacity and atherosclerotic cardiovascular disease in patients with familial hypercholesterolemia. Arterioscler Thromb Vasc Biol. 2016;36:181-8.

18. Chan DC, Pang J, Hooper AJ, Burnett JR, Bell DA, Bates TR, et al. Elevated lipoprotein(a), hypertension and renal insufficiency as predictors of coronary artery disease in patients with genetically confirmed heterozygous familial hypercholesterolemia. Int J Cardiol. 2015;201:633-8.

19. Alonso R, Andres E, Mata N, Fuentes-Jiménez F, Badimón L, López-Miranda J, et al. Lipoprotein(a) levels in familial hypercholesterolemia: an important predictor of cardiovascular disease independent of the type of LDL receptor mutation. J Am Coll Cardiol. 2014;63:1982-9.
20. Raal FJ, Santos RD. Homozygous familial hypercholesterolemia: current perspectives on diagnosis and treatment. Atherosclerosis. 2012;223:262-8.

21. Santos PC, Pereira AC. Type of LDLR mutation and the pharmacogenetics of familial hypercholesterolemia treatment. Pharmacogenomics. 2015;16:1743-50.

22. Carmena R, Roederer G, Mailloux H, et al. The response to lovastatin treatment in patients with heterozygous familial hypercholesterolemia is modulated by apolipoprotein E polymorphism. Metabolism. 1993;42:895-901.

23. Feng Q, Wei WQ, Chung CP, Levinson RT, Bastarache L, Denny $\mathrm{JC}$, et al. The effect of genetic variation in PCSK9 on the LDLcholesterol response to statin therapy. Pharmacogenomics J. 2017;17:204-8.

24. Postmus I, Trompet S, Deshmukh HA, et al. Pharmacogenetic meta-analysis of genome-wide association studies of LDL cholesterol response to statins. Nat Commun. 2014;5:5068.

25. Avis HJ, Vissers MN, Stein EA, Wijburg FA, Trip MD, Kastelein JJP, et al. A systematic review and meta-analysis of statin therapy in children with familial hypercholesterolemia. Arterioscler Thromb Vasc Biol. 2007;27:1803-10.

26. Mamann N, Lemale J, Karsenty A, Dubern B, Girardet JP, Tounian P. Intermediate-term efficacy and tolerance of statins in children. J Pediatr. 2019;210:161-5.

27.• Vuorio A, Kuoppala J, Kovanen PT, et al. Statins for children with familial hypercholesterolemia. Cochrane Database Syst. 2019;11: CD006401. https://doi.org/10.1002/14651858.CD006401.pub5 A large meta-analysis supports the efficacy and safety of statin therapy in children and adolescents.

28. Braamskamp MJ, Kusters DM, Avis HJ, et al. Long-term statin treatment in children with familial hypercholesterolemia: more insight into tolerability and adherence. Paediatr Drugs. 2015;17: $159-66$.

29. Kusters DM, Avis HJ, de Groot E, Wijburg FA, Kastelein JJP, Wiegman A, et al. Ten-year follow-up after initiation of statin therapy in children with familial hypercholesterolemia. JAMA. 2014;312:1055-7.

30. Wiegman A, Gidding SS, Watts GF, Chapman MJ, Ginsberg HN, Cuchel M, et al. Familial hypercholesterolaemia in children and adolescents: gaining decades of life by optimizing detection and treatment. Eur Heart J. 2015;36:2425-37.

31. Watts GF, Gidding S, Wierzbicki AS, et al. Integrated guidance on the care of familial hypercholesterolaemia from the International FH Foundation. Int J Cardiol. 2014;171:309-25.

32. Ramaswami U, Humphries SE, Priestley-Barnham L, et al. Current management of children and young people with heterozygous familial hypercholesterolaemia-HEART UK statement of care. Atherosclerosis. 2019;290:1-8 Recent recommendations for the management of $\mathbf{F H}$ in children and adolescents.

33. Harada-Shiba M, Ohta T, Ohtake A, Ogura M, Dobashi K, Nohara A, et al. Guidance for pediatric familial hypercholesterolemia 2017. J Atheroscler Thromb. 2018;25:539-53.

34. Braamskamp MJ, Langslet G, McCrindle BW, et al. Effect of rosuvastatin on carotid intima-media thickness in children with heterozygous familial hypercholesterolemia: the CHARON study. Circulation. 2017;136:359-66.

35. Braamskamp MJ, Langslet G, McCrindle BW, et al. Efficacy and safety of rosuvastatin therapy in children and adolescents with familial hypercholesterolemia: results from the CHARON study. J Clin Lipidol. 2015;9:741-50.

36.• Luirink I, Wiegman A, Kusters D, et al. 20-year follow-up of statins in children with familial hypercholesterolaemia. N Engl J Med. 2019;381:1547-56 This study supports the long-term cardiovascular benefits for statin therapy in children.

37. Ference BA, Yoo W, Alesh I, Mahajan N, Mirowska KK, Mewada A, et al. Effect of long-term exposure to lower low- 
density lipoprotein cholesterol beginning early in life on the risk of coronary heart disease: a Mendelian randomization analysis. J Am Coll Cardiol. 2012;60:2631-9.

38. Ference BA, Schunkert H, Watts GF, et al. Low-density lipoproteins cause atherosclerotic cardiovascular disease. 1. Evidence from genetic, epidemiologic, and clinical studies. A consensus statement from the European Atherosclerosis Society Consensus Panel. Eur Heart J. 2017;38:2459-72.

39. Perez de Isla L, Alonso R, Watts GF, et al. Attainment of LDLcholesterol treatment goals in patients with familial hypercholesterolemia: 5-year SAFEHEART registry follow-up. J Am Coll Cardiol. 2016;67:1278-85.

40. Versmissen J, Oosterveer DM, Yazdanpanah M, Defesche JC, Basart DCG, Liem AH, et al. Efficacy of statins in familial hypercholesterolaemia: a long term cohort study. Br Med J. 2008;337: a2423.

41. Neil A, Cooper J, Betteridge J, Capps N, McDowell I, Durrington P, et al. Reductions in all-cause, cancer, and coronary mortality in statintreated patients with heterozygous familial hypercholesterolaemia: a prospective registry study. Eur Heart J. 2008;29:2625-33.

42.• Nayak A, Hayen A, Zhu L, et al. Legacy effects of statins on cardiovascular and all-cause mortality: a meta-analysis. BMJ Open. 2018:e20584 A meta-analysis that supports the posttrial statin legacy on cardiovascular disease and all-cause mortality.

43.•- Pérez de Isla L, Arroyo-Olivares R, Muñiz-Grijalvo O, et al. Long-term effect of 2 intensive statin regimens on treatment and incidence of cardiovascular events in familial hypercholesterolemia: the SAFEHEART study. J Clin Lipidol. 2019;13:989-96 A large registry data analysis that supports the long-term use of statins for the prevention of cardiovascular disease in FH.

44. Raal FJ, Pilcher GJ, Panz VR, van Deventer HE, Brice BC, Blom DJ, et al. Reduction in mortality in subjects with homozygous familial hypercholesterolemia associated with advances in lipidlowering therapy. Circulation. 2011;124:2202-7.

45. Humphries S, Cooper J, Seed M, Capps N, Durrington PN, Jones $\mathrm{B}$, et al. Coronary heart disease mortality in treated familial hypercholesterolaemia: update of the UK Simon Broome FH register. Atherosclerosis. 2018;274:41-6.

46. Bos S, Duvekot MHC, ten Kate G-JR, Verhoeven AJM, Mulder MT, Schinkel AFL, et al. Carotid artery plaques and intima medial thickness in familial hypercholesteraemic patients on long-term statin therapy: a case control study. Atherosclerosis. 2017;256: 62-6.

47. Smilde TJ, van Wissen $\mathrm{S}$, Wollersheim $\mathrm{H}$, et al. Effect of aggressive versus conventional lipid lowering on atherosclerosis progression in familial hypercholesterolaemia (ASAP): a prospective, randomised, double-blind trial. Lancet. 2001;357:577-81.

48. Moroi M, Nagayama D, Hara F, Saiki A, Shimizu K, Takahashi $\mathrm{M}$, et al. Outcome of pitavastatin versus atorvastatin therapy in patients with hypercholesterolemia at high risk for atherosclerotic cardiovascular disease. Int J Cardiol. 2020;305:139-46.

49. Vallejo-Vaz AJ, Robertson M, Catapano AL, et al. Low-density lipoprotein cholesterol lowering for the primary prevention of cardiovascular disease among men with primary elevations of lowdensity lipoprotein cholesterol levels of $190 \mathrm{mg} / \mathrm{dL}$ or above: analyses from the WOSCOPS (West of Scotland coronary prevention study) 5-year randomized trial and 20-year observational follow-up. Circulation. 2017;136:1878-91.

50. Amundsen AL, Khoury J, Iversen PO, Bergei C, Ose L, Tonstad $\mathrm{S}$, et al. Marked changes in plasma lipids and lipoproteins during pregnancy in women with familial hypercholesterolemia. Atherosclerosis. 2006;189:451-7.

51. Eapen DJ, Valiani K, Reddy S, Sperling L. Management of familial hypercholesterolemia during pregnancy: case series and discussion. J Clin Lipidol. 2012;6:88-91.
52. Toleikyte I, Rettterstol K, Leren TP, et al. Pregnancy outcomes in familial hypercholesterolemia: a registry-based study. Circulation. 2011;124:1606-14.

53. Wierzbicki AS, Humphries SE, Minhas R. Guideline Development Group. Familial hypercholesterolaemia: summary of NICE guidelines. BMJ. 2008;337:a1095.

54. Botha TC, Pilcher GJ, Wolmarans K, et al. Statins and other lipidlowering therapy and pregnancy outcomes in homozygous familial hypercholesterolaemia: a retrospective review of 39 pregnancies. Atherosclerosis. 2018;277:502-7 This study supports the safety of statin therapy in FH during pregnancy.

55. Cholesterol Treatment Trialists' Collaboration. Efficacy and safety of statin therapy in older people: a meta-analysis of individual participant data from 28 randomised controlled trials. Lancet. 2019;393:407-15 A large meta-analysis that supports the efficacy and safety of statin therapy in older people.

56. Ward NC, Watts GF, Eckel RH. Statin toxicity: mechanistic insights and clinical implications. Circ Res. 2019;124:328-50 A comprehensive review on statin intolerance and toxicity.

57. de Goma EM, Ahmad ZS, O'Brien EC, et al. Treatment gaps in adults with heterozygous familial hypercholesterolemia in the United States: Data from the CASCADE-FH Registry. Circ Cardiovasc Genet. 2016;9:240-9.

58. Toth PP, Patti AM, Giglio RV, Nikolic D, Castellino G, Rizzo M, et al. Management of statin intolerance in 2018: still more questions than answers. Am J Cardiovasc Drugs. 2018;18:157-73.

59. De Vera MA, Bhole V, Burns LC, Lacaille D. Impact of statin adherence on cardiovascular disease and mortality outcomes: a systematic review. Br J Clin Pharmacol. 2014;78:684-98.

60. Rodriguez F, Maron DJ, Knowles JW, et al. Association of statin adherence with mortality in patients with atherosclerotic cardiovascular disease. JAMA Cardiol. 2019;4:206-13.

61. Galema-Boers JM, Lenzen MJ, van Domburg RT, et al. Predicting non-adherence in patients with familial hypercholesterolemia. Eur J Clin Pharmacol. 2014;70:391-7.

62. Hagger MS, Hardcastle SJ, Hu M, Kwok S, Lin J, Nawawi HM, et al. Effects of medication, treatment, and behavioral beliefs on intentions to take medication in patients with familial hypercholesterolemia. Atherosclerosis. 2018;277:493-501.

63. Matthews A, Herrett E, Gasparrini A, et al. Impact of statin related media coverage on use of statins: interrupted time series analysis with UK primary care data. BMJ. 2016;353.

64. Nielsen SF, Nordestgaard BG. Negative statin-related news stories decrease statin persistence and increase myocardial infarction and cardiovascular mortality: a nationwide prospective cohort study. Eur Heart J. 2016;37:908-16.

65.• Watts GF, Gidding SS, Mata P et al. Familial hypercholesterolaemia: evolving knowledge for designing adaptive models of care. Nat Rev Cardiol. 2020;17:360-377. A comprehensive review on the contemporary management of $\mathrm{FH}$.

66. Pang J, Sullivan DR, Brett T, Kostner KM, Hare DL, Watts GF. Familial hypercholesterolaemia in 2020: a leading tier 1 genomic application. Heart Lung Circ. 2020;29:619-33.

67. Naito R, Miyauchi K, Daida H. Racial differences in the cholesterol-lowering effect of statin. J Atheroscler Thromb. 2017;24:19-25.

68. Hu M, Lui SS, Ko GT, et al. Do the lipid responses to rosuvastatin and atorvastatin differ between Chinese and Caucasians? Comparison of the DISCOVERY-Hong Kong study with other DISCOVERY studies. Int J Cardiol. 2013;168:3071-3.

69. Yang J, Li LJ, Wang K, He YC, Sheng YC, Xu L, et al. Race differences: modeling the pharmacodynamics of rosuvastatin in Western and Asian hypercholesterolemia patients. Acta Pharmacol Sin. 2011;32:116-25.

70. Tomlinson B, Chan P, Liu ZM. Statin responses in Chinese patients. J Atheroscler Thromb. 2018;25:199-202. 
71. Harada-Shiba M, Kastelein JJP, Hovingh GK, Ray KK, Ohtake A, Arisaka $\mathrm{O}$, et al. Efficacy and safety of pitavastatin in children and adolescents with familial hypercholesterolemia in Japan and Europe. J Atheroscler Thromb. 2018;25:422-9.

72. Vuorio A, Watts GF, Schneider WJ, et al. Familial hypercholesterolemia and elevated lipoprotein(a): double heritable risk and new therapeutic opportunities. J Intern Med. 2020;287:2-18 A comprehensive review on the association of $L p(a)$ and ASCVD in FH.

73.• Tsimikas S, Gordts PLSM, Nora C, et al. Statin therapy increases lipoprotein(a) levels. Eur Heart J. 2020;41:2275-84. https://doi. org/10.1093/eurheartj/ehz310 A large meta-analysis on the effect of statin therapy on $\mathrm{Lp}(\mathrm{a})$ levels.

74. Yahya R, Berk K, Verhoeven A, Bos S, van der Zee L, Touw J, et al. Statin treatment increases lipoprotein(a) levels in subjects with low molecular weight apolipoprotein(a) phenotype. Atherosclerosis. 2019;289:201-5.

75. Trinder M, DeCastro ML, Azizi H, et al. Ascertainment bias in the association between elevated lipoprotein(a) and familial hypercholesterolemia. J Am Coll Cardiol. 2020;75:2682-93. https:// doi.org/10.1016/j.jacc.2020.03.065.

76. Neefjes LA, Ten Kate GJ, Alexia R, et al. Accelerated subclinical coronary atherosclerosis in patients with familial hypercholesterolemia. Atherosclerosis. 2011;219:721-7.

77. Miname MH, Ribeiro MS, Parga Filho J, et al. Evaluation of subclinical atherosclerosis by computed tomography coronary angiography and its association with risk factors in familial hypercholesterolemia. Atherosclerosis. 2010;213:486-91.

78.• Miname MH, Bittencourt MS, Moraes SR, et al. Coronary artery calcium and cardiovascular events in patients with familial hypercholesterolemia receiving standard lipid-lowering therapy. JACC Cardiovasc Imaging. 2019;12:1797-804 An imaging study that supports the use of CACS to stratify near-term risk in FH patients.

79. Puri R, Nicholls SJ, Shao M, Kataoka Y, Uno K, Kapadia SR, et al. Impact of statins on serial coronary calcification during atheroma progression and regression. J Am Coll Cardiol. 2015;65: 1273-82.

80. Henein M, Granasen G, Wiklund U, et al. High dose and longterm statin therapy accelerate coronary artery calcification. Int $\mathrm{J}$ Cardiol. 2015;184:581-6.

81. Lee SE, Sung JM, Andreini D, Budoff MJ, Cademartiri F, Chinnaiyan K, et al. Differential association between the progression of coronary artery calcium score and coronary plaque volume progression according to statins: the Progression of AtheRosclerotic PlAque DetermIned by Computed TomoGraphic Angiography Imaging (PARADIGM) study. Eur Heart J Cardiovasc Imaging. 2019;20:1307-14.

82. Knuuti J, Wijns W, Saraste A, Capodanno D, Barbato E, FunckBrentano C, et al. 2019 ESC Guidelines for the diagnosis and management of chronic coronary syndromes: The Task Force for the diagnosis and management of chronic coronary syndromes of the European Society of Cardiology (ESC). Eur Heart J. 2020;41:407-77.

83. Castiglione V, Chiriacò M, Emdin M, et al. Statin therapy in COVID-19 infection. Eur Heart J Cardiovasc Pharmacother. 2020;6:258-9. https://doi.org/10.1093/ehjcvp/pvaa042.

84. Babelova A, Sedding DG, Brandes RP. Anti-atherosclerotic mechanisms of statin therapy. Curr Opin Pharmacol. 2013;13: $260-4$.

85. Zeiser R. Immune modulatory effects of statins. Immunology. 2018;154:69-75.
86. Driggin E, Madhavan MV, Bikdeli B, Chuich T, Laracy J, BiondiZoccai G, et al. Cardiovascular considerations for patients, health care workers, and health systems during the COVID-19 pandemic. J Am Coll Cardiol. 2020;75:2352-71.

87. Guan WJ, Ni ZY, Hu Y, Liang WH, Ou CQ, He JX, et al. Clinical characteristics of coronavirus disease 2019 in China. N Engl J Med. 2020;382:1708-20.

88. Vuorio A, Watts GF, Kovanen PT. Familial hypercholesterolaemia and COVID-19: triggering of increased sustained cardiovascular risk. J Intern Med. 2020;287:746-7 A brief review on the management of FH patients with COVID-19.

89. Alirocumab for treating primary hypercholesterolaemia and mixed dyslipidaemia [https://www.nice.org.uk/guidance/ta393].

90. Evolocumab for treating primary hypercholesterolaemia and mixed dyslipidaemia [https://www.nice.org.uk/guidance/ta394].

91. Barton Duell P, Gidding SS, Andersen RL, et al. Longitudinal low density lipoprotein cholesterol goal achievement and cardiovascular outcomes among adult patients with familial hypercholesterolemia: the CASCADE FH registry. Atherosclerosis. 2019;289:8593 This study supports earlier and more aggressive therapy of FH to prevent ASCVD events.

92. Defesche JC, Stefanutti C, Langslet G, et al. Efficacy of alirocumab in 1191 patients with a wide spectrum of mutations in genes causative for familial hypercholesterolemia. J Clin Lipidol. 2017;11:1338-46 This study supports the use of PCSK9 inhibitors in patients with FH.

93. Raal FJ, Hovingh GK, Catapano AL. Familial hypercholesterolemia treatments: guidelines and new therapies. Atherosclerosis. 2018;277:483-92.

94. Lázaro P, Pérez de Isla L, Watts GF, et al. Cost-effectiveness of a cascade screening program for the early detection of familial hypercholesterolemia. J Clin Lipidol. 2017;11:260-71.

95. Ademi Z, Norman R, Pang J, et al. Health economic evaluation of screening and treating children with familial hypercholesterolemia early in life: many happy returns on investment? Atherosclerosis. 2020;304:1-8. https://doi.org/10.1016/j.atherosclerosis.2020.05. 007 This study supports the cost-effectiveness for screening and treating children with $\mathbf{F H}$.

96. Klančar G, Grošelj U, Kovač J, Bratanič N, Bratina N, Trebušak Podkrajšek K, et al. Universal screening for familial hypercholesterolemia in children. J Am Coll Cardiol. 2015;66:1250-7.

97. Wald DS, Bestwick JP, Morris JK, Whyte K, Jenkins L, Wald NJ. Child-parent familial hypercholesterolemia screening in primary care. N Engl J Med. 2016;375:1628-37.

98. Athyros VG, Boutari C, Imprialos K, et al. Inclisiran. A new kid on the new block for treating hypercholesterolaemia. Curr Vasc Pharmacol. 2020. https://doi.org/10.2174/ 1570161118999200428225849

99. Hibbitt O, Agkatsev S, Owen C, et al. RNAi-mediated knockdown of HMG CoA reductase enhances gene expression from physiologically regulated low-density lipoprotein receptor therapeutic vectors in vivo. Gene Ther. 2012;9:463-7.

100. Tsimikas S, Karwatowska-Prokopczuk E, Gouni-Berthold I, Tardif JC, Baum SJ, Steinhagen-Thiessen E, et al. Lipoprotein(a) reduction in persons with cardiovascular disease. N Engl J Med. 2020;382:244-55.

Publisher's Note Springer Nature remains neutral with regard to jurisdictional claims in published maps and institutional affiliations. 